\title{
Tissue Factor and Tissue Factor Pathway Inhibitor as Key Regulators of Global Hemostasis: Measurement of Their Levels in Coagulation Assays
}

\author{
Raj S. Kasthuri, M.D. ${ }^{1}$, Sam L. Glover ${ }^{1}$, Jeremiah Boles, M.D. ${ }^{1}$, and Nigel Mackman, Ph.D. ${ }^{1}$ \\ ${ }^{1}$ Division of Hematology and Oncology, Department of Medicine, The University of North Carolina \\ at Chapel Hill, Chapel Hill, North Carolina.
}

\begin{abstract}
The tissue factor (TF)/factor (F)VIIa complex is the primary initiator of coagulation in vivo. Tissue factor pathway inhibitor (TFPI) is the physiological inhibitor of the TF/FVIIa complex. Deficiencies of either TF or TFPI have not been reported in humans, and a complete absence of either of these two proteins in mice is embryonically lethal. To maintain normal hemostasis, levels of TF and TFPI need to be balanced. Increased levels of TF can overwhelm the inhibitory capacity of TFPI, resulting in thrombosis. Decreased levels of TF are associated with bleeding. Global assays of coagulation are defined as tests capable of evaluating all components of the clotting cascade that are present in plasma. In these tests the thrombogenic surface is either provided by platelets or exogenous phospholipids. Clotting assays currently used in clinical practice are not designed to measure endogenous levels of TF and TFPI. Therefore, there is a need to develop sensitive and specific assays for measuring levels of functional TF and TFPI in whole blood and plasma. These assays could be useful in patient management in many scenarios.
\end{abstract}

\section{Keywords}

Tissue factor; tissue factor pathway inhibitor; thrombosis; thromboelastography

\begin{abstract}
Significant progress has been made over the last decade in understanding the many complex interactions involved in the process of blood coagulation. The care ofpatientswithdisordersofthrombosisisalsoentering a new era with many new treatment modalities in varying stages of development, including new oral anticoagulants, aptamers targeted against coagulation factors and the use of natural anticoagulants. ${ }^{1,2}$ In addition, hemophilia patients with inhibitors can be treated with recombinant factor (F)VIIa, and possibly in the future with drugs that interfere with the activity of anticoagulant proteins, such as tissue factor pathway inhibitor (TFPI). In keeping with these advances, ongoing efforts are aimed at improving our ability to identify at-risk patients, such as those at risk for bleeding or those at risk for venous thromboembolism (VTE). Successful risk stratification has the advantage of both improving outcomes and decreasing the number of patients exposed to unnecessary interventions. This review briefly discusses the role of tissue factor (TF) and TFPI in hemostasis and the measurement of endogenous levels of these proteins in whole blood and plasma.
\end{abstract}

Copyright @ 2010 by Thieme Medical Publishers, Inc., 333 Seventh Avenue, New York, NY 10001, USA. Tel: +1(212) 584-4662.

Address for correspondence and reprint requests: Nigel Mackman, Ph.D., UNC Chapel Hill, 917 Mary Ellen Jones Building, CB7035, Chapel Hill, NC 27599 (nmackman@med.unc.edu)..

Global Hemostasis: New Approaches to Patient Diagnosis and Treatment Monitoring; Guest Editor, Maha Othman, M.D., Ph.D. 


\section{ROLES OF TISSUE FACTOR AND TISSUE FACTOR PATHWAY INHIBITOR IN HEMOSTASIS}

\section{Tissue Factor}

TF is a transmembrane glycoprotein (263 amino acids; molecular weight [MW] $47 \mathrm{kDa}$ ) that functions as the receptor for plasma FVII/VIIa. The TF/FVIIa complex is the primary initiator of coagulation in vivo. ${ }^{3}$ This binary complex activates coagulation factors, FX and FIX, resulting in thrombin generation, fibrin deposition, and, together with platelets, the formation of a hemostatic plug.

TF is constitutively expressed by perivascular cells, which ensures rapid activation of coagulation at sites of vascular damage. TF is also constitutively expressed in the brain, heart, lung, kidney, and placenta, where it provides additional tissue-specific hemostatic protection to these vital organs. The importance of TF in these organs is underscored by the development of hemorrhages in the brain, lung, and heart in mice expressing low levels of TF or FVIIa. A genetic deficiency of TF has not been described in humans, and a complete absence of TF is embryonically lethal in mice. ${ }^{4} \mathrm{TF}$ expression can also be induced in a variety of cells, such as monocytes, and this expression can lead to the development of thrombosis in pathological conditions like sepsis. In healthy individuals, very low levels of $\mathrm{TF}$ antigen are present in blood, primarily on a subset of monocytes and circulating microparticles (MPs). These are submicron membrane vesicles that are released from activated cells or cells undergoing apoptosis. It has been proposed that circulating MP TF may trigger venous thrombosis and deliver TF to a developing thrombus. This is more likely to occur in pathological conditions where levels of TF-positive MPs are elevated.

In 2003, Nemerson and colleagues described a novel form of TF that is commonly referred to as alternatively spliced TF (altTF) or soluble TF because it lacks the transmembrane anchor domain. Initially, it was felt that this form of TF was thrombotic, but subsequent data have demonstrated that altTF lacks procoagulant activity. ${ }^{5}$

Calcium ionophore treatment of TF-bearing cells increases TF activity several fold. This indicated that TF exists in two different states: low activity and high activity. Potential mechanisms for this increase in activity have been reviewed. ${ }^{6}$ Some authors argue that this increase in TF activity is due to an interaction between TF and the anionic membrane phospholipid phosphatidylserine (PS). Normally, PS is maintained asymmetrically on the inner cell membrane layer but becomes exposed on the cell surface upon cell stimulation or membrane disruption, thereby allowing interaction with the extracellular domain of TF.

\section{Tissue Factor Pathway Inhibitor}

TFPI is a Kunitz-type protease inhibitor (276 amino acids; $\mathrm{MW} \sim 42 \mathrm{kDa}$ ) and is the primary physiological inhibitor of the TF/FVIIa complex. TFPI has three Kunitz domains (K1-3). $\mathrm{K} 1$ binds FVIIa and $\mathrm{K} 2$ binds FXa. ${ }^{7} \mathrm{~K} 3$ is involved in lipoprotein binding and also contains a heparin binding site, although its role in the inhibition of coagulation is yet to be established. There are several splice variants of TFPI. TFPI $\alpha$ is the only form with the K3 domain, whereas all other known splice variants contain K1 and K2 domains but not K3. The physiological relevance of the splice variants of TFPI is not clear. Under normal conditions TFPI is mostly expressed by vascular endothelial cells. However, lower levels of TFPI are expressed by megakaryocytes, monocytes, lung fibroblasts, and synovial cells. TFPI $\alpha$ associates with cells primarily via a glycosylphosphatidylinositol (GPI) anchor, although a small amount of TFPI is nonspecifically bound to surface glycosaminoglycans via its $\mathrm{C}$-terminus. However, the C-terminus of TFPI $\alpha$ does not contain a GPI anchor 
sequence, and it is therefore speculated that TFPI binds to the cell surface by interacting with an as yet unidentified GPI-anchored protein. ${ }^{7}$

The vast majority of TFPI in the body is bound to the endothelium, and a smaller portion is bound to the surface of monocytes. Only $\sim 20 \%$ of TFPI is present in the plasma where the majority is bound to low-density lipoproteins and only $\sim 2 \%$ is unbound.

TFPI inhibits the TF/FVIIa complex via a two step process. First, TFPI forms a bimolecular complex with FXa, which then forms a quaternary complex with TF/FVIIa. It was recently demonstrated that protein $\mathrm{S}$ acts as a cofactor for TFPI. ${ }^{8}$ Protein $\mathrm{S}$ enhances TFPI-mediated inhibition of FXa by $\sim 10$-fold. Interestingly, this cofactor activity of protein $\mathrm{S}$ requires the presence of the $\mathrm{K} 3$ domain of TFPI.

Similar to TF, a genetic deficiency of TFPI has not been described in humans, and a complete absence of TFPI in mice is embryonically lethal. This embryonic lethality can be overcome by dramatically reducing levels of $\mathrm{TF}$, highlighting the importance of maintaining a balance between TF and TFPI (Fig. 1).

\section{Role of Tissue Factor and Tissue Factor Pathway Inhibitor in Disease}

Given the essential roles of TF and TFPI in hemostasis, it would intuitively follow that alteration in the balance between the two proteins would lead to the development of either thrombosis or bleeding (Fig. 1). For instance, either increased levels of TF and/or decreased levels of TFPI would lead to thrombosis. In addition, such conditions could reduce bleeding in individuals with hemophilia. VTE is used here as an example to illustrate the changes that occur in levels of TF and TFPI in disease.

TISSUE FACTOR IN VENOUS THROMBOEMBOLISM-Injury to the vessel wall results in the exposure of perivascular TF to blood and initiation of coagulation. Although this is a normal physiological response to injury, an excessive response can result in pathological thrombosis in certain settings, such as in trauma and in postsurgical patients. TF expression can also be induced in monocytes in disease states, such as sepsis, resulting in disseminated intravascular coagulation.

Thrombosis is a common and well-known complication in cancer patients. The risk of thrombosis in cancer varies depending on the type of cancer, with glioblastoma, pancreatic cancer, and gastric cancer conferring significantly higher risk for thrombosis as compared with breast cancer. In addition, chemotherapy further increases the underlying thrombotic risk, and again, the risk conferred by certain agents is significantly greater than others. ${ }^{9}$ The mechanism of thrombosis in cancer remains unclear and is likely to be multifactorial. One possible mechanism is the release of TF-positive MPs from tumor cells into the circulation resulting in the activation of coagulation and the development of thrombosis. ${ }^{10}$

Several reports in the literature support a role for TF in the development of thrombosis in cancer. TF is expressed by almost all cancer cells. In mouse models of both pancreatic and colorectal cancer, there is an increase inTF inthe blood. ${ }^{10}$ In humans, the risk for thrombosis is highest in patients with gliomas and pancreatic cancer, and both these tumors have been found to express high levels of TF. In 2007, it was demonstrated that an increase in TFpositive MPs correlated with both the development of VTE and decreased overall survival in patients with pancreatic cancer. ${ }^{11} \mathrm{~A}$ second study in a small cohort of pancreatic cancer patients found that levels of MP TF activity increased over several weeks and preceded the development of VTE. ${ }^{12}$ 
TISSUE FACTOR PATHWAY INHIBITOR IN VENOUS THROMBOEMBOLISM-A low level of circulating TFPI has been shown to be a risk factor for developing VTE. For instance, among participants in the Leiden Thrombophilia Study, individuals with free TFPI levels $<10$ th percentile had a slightly increased odds ratio (OR) for developing deep vein thrombosis (DVT) (OR: 1.7; confidence interval (CI), 1.1 to 2.6).$^{13}$ Total plasma TFPI (i.e., lipoprotein bound as well as unbound TFPI) values $<10$ th percentile of normal controls were also associated with the development of thrombosis and stroke in children (OR: 3.8; CI, 2.2 to 6.6) ${ }^{14}$ In addition, low levels of heparin-releasable TFPI were found in young adults with venous and arterial thrombosis compared with controls. ${ }^{15}$ Reduced levels of TFPI have been demonstrated in women taking oral contraceptives or treated with hormone replacement therapy, which may be one of the mechanisms for the increased thrombotic risk in this setting. ${ }^{16}$ In a case-control study with 122 DVT patients, the total TFPI level was significantly lower in patients with DVT compared with 126 controls. ${ }^{17}$ In contrast to this, a recent study found that plasma-free and total TFPI levels were significantly higher in patients with acute DVT. ${ }^{18}$ Further, the levels of free and total TFPI correlated with the extent of fibrin formation as measured using a D-dimer test. The C-terminal fragment of TFPI can bind fibrin, and it is speculated that this increase in TFPI is related to the release of fibrin-bound TFPI during fibrin degradation. Finally, among participants in the Austrian Study on Recurrent Venous Thromboembolism, a prospective multicenter study on the risk factors for recurrent VTE, low levels of free TFPI, <2nd percentile, were associated with an increased risk for recurrent VTE (relative risk [RR]: 2.7 ; CI, 1 to 7.4 ). ${ }^{19}$

When evaluating studies on the role of TFPI in disease states, it is important to point out some limitations: (1) there is a wide range of TFPI among normal individuals, and (2) several of the studies on TFPI and risk for thrombosis are retrospective or case controlled and do not address whether the low levels of TFPI are the cause or the effect of the thrombotic event. Unfortunately, there remains a paucity of prospective studies evaluating the role of TFPI in the development of VTE. Based on available data in the literature, there is a lack of compelling evidence that a low TFPI level in itself is a significant risk factor for the development of thrombosis. Similarly, no evidence indicates that an elevated level of TFPI confers an increased risk for bleeding.

In summary, if TF levels exceed a certain threshold, it will overwhelm the inhibitory regulation by TFPI, resulting in a propensity toward thrombosis. This may also explain why the imbalance between TF and TFPI appears to be significant only when it results in increased TF and not vice versa.

\section{CAN LABORATORY COAGULATION ASSAYS MEASURE ENDOGENOUS LEVELS OF TISSUE FACTOR AND TISSUE FACTOR PATHWAY INHIBITOR?}

Global coagulation assays are defined as tests capable of evaluating all components of coagulation in the presence of a thrombogenic surface that can be provided by either platelets or exogenous phospholipids. Activated platelets also release their granular contents, which include coagulation factors that will shorten clotting times. There is a need to develop better global assays of coagulation for use in the clinical setting. Laboratory tests, such as the prothrombin time (PT), activated partial thromboplastin time (aPTT), and the thrombin time (TT), are frequently used in the clinical setting to assess the activity of the coagulation system and the risk for bleeding. These plasma-based assays are performed on platelet-poor plasma (PPP) with exogenous phospholipids. The following is a discussion of currently available laboratory assays and their ability to measure levels of functional TF and TFPI (listed in Table 1). 


\section{Plasma-Based Clotting Assays PROTHROMBIN TIME AND ACTIVATED PARTIAL THROMBOPLASTIN TIME-}

The PT and aPTT are the most widely used laboratory tests of coagulation. These tests are performed using plasma and clotting times are measured after the addition of exogenous phospholipid and either an activator of the extrinsic pathway (thromboplastin; PT test) or an activator of the intrinsic (contact) pathway (kaolin, micronized silica, etc; aPTT test). Therefore, these tests tend to detect derangements in the initiation and propagation phases of coagulation. However, these tests do not provide much information about global coagulation due to the high concentrations of activators used. They are not useful in evaluating the levels of either TF or TFPI.

THROMBIN TIME-The TT is a plasma-based assay that measures thrombin-mediated conversion of fibrinogen to fibrin and is a useful test to measure the integrity of the final step of the coagulation cascade, (i.e., fibrin generation). This test uses exogenous thrombin and has the same disadvantages of the PT and aPTT previously discussed.

CALIBRATED AUTOMATED THROMBOGRAM-The calibrated automated thrombogram (CAT) assay measures thrombin generation in either fresh platelet-rich plasma (PRP) or PPP with exogenous phospholipids. Usually low levels of exogenous recombinant $\mathrm{TF}$ are added to initiate coagulation in the CAT assay, which makes it more sensitive than the standard PT and aPTT assays. The CAT assay can also be used to measure the procoagulant activity of MPs. Addition of a mixture of phospholipids is required to ensure that levels of phospholipid are not limiting. The assay measures thrombin generation by detecting thrombin-mediated cleavage of a fluorogenic substrate. A so-called thrombogram is produced (Fig. 2) that can be used to calculate lag time (LT), peak thrombin, and endogenous thrombin potential. The usefulness of the CAT assay has been evaluated in several different clinical settings, such as monitoring warfarin therapy and the adequacy of factor replacement therapy in hemophilia patients. Thus far, there is insufficient evidence to support routine use of the CAT assay in clinical practice.

We evaluated the ability of the CAT assay to measure endogenous TF in both fresh PRP and PPP. ${ }^{20}$ We used PRP and PPP from unstimulated and lipopolysaccharide (LPS) stimulated whole blood induced TF expression that was associated with a shorter LT without a change in peak thrombin (Fig. 2). ${ }^{20}$ Another group found that plasma isolated from LPS treated blood had a shorter LT and a higher peak height compared with control plasma. ${ }^{21} \mathrm{In}$ evaluating the ability of the CAT assay to detect MP TF, we found that addition of exogenous phospholipid decreased the TF dependence of the assay. Overall, the CAT assay is likely the best global assay for the evaluation of levels of TF activity in fresh PRP and fresh or frozen PPP. However, the levels of TF generated in whole blood treated with LPS most likely far exceed the levels of circulating TF that will occur in a clinical setting. This means it is unlikely that the CAT assay will be sensitive enough to detect levels of circulating TF in patients due to the presence of endogenous TFPI and other anticoagulants in the plasma. Nevertheless, further studies are needed to determine if the CAT assay can be used to detect endogenous TF in clinical samples.

\section{Whole Blood Clotting Assays}

Whole blood clotting assays arearguablymoresensitive measures of global coagulation, and several such assays have been developed over the years. Some of the earlier assay and the more recently developed thromboelastogram are discussed later. However, a major problem with all these assays is the large intra- and interassay variability. 
ACTIVATED CLOTTING TIME/LEE WHITE CLOTTING TIME-Both the activated clotting time (ACT) and the Lee-White clotting time are whole blood clotting assays that can be performed on fresh or citrated whole blood. The assays involve activation of the intrinsic system using an activator (kaolin, ACT) or collection of blood in non-siliconized tubes (Lee-White). In either case, citrated blood samples are recalcified and clotting times measured. Although these tests may be regarded as tests of global coagulation, they have limitations. First, there is a significant variation in these clotting times among healthy individuals. One can therefore imagine instances where an individual may have significantly prolonged clotting times on these assays compared with his or her own baseline but still fall within the upper limit of the normal range, thereby resulting in a false-negative test. In addition, although these tests may be sensitive for detection of coagulation defects, they are not specific given the number of different variables that influence the clotting time. Indeed, this is a drawback for all whole blood assays. Finally, because these tests involve activation of the contact pathway, they do not provide useful information on the levels of TF and TFPI.

TISSUE FACTOR CLOTTING TIME-This is another whole blood assay that measures time to clot formation. The assay is simple and measures the clotting time of recalcified citrated blood. It was shown that LPS treatment of whole blood shortened the clotting time in a TF-dependent manner. However, addition of anti-TF antibodies to unstimulated blood from healthy individuals did not change the clotting time, indicating that the level of endogenous TF was below the detectable limit of the assay. ${ }^{22}$ Marsik and colleagues ${ }^{23}$ showed that the tissue factor clotting time was shortened in a time-dependent manner in blood collected from volunteers given LPS and that this shortening was partially reversed by an anti-TF antibody. However, additional studies are needed to determine if this assay can be used to reliably detect levels of functional TF in clinical samples. Moreover, the coefficient of variation was also quite large, suggesting that this assay would not be useful as a clinical assay. Finally, the contact activation system is activated in citrated blood, which makes it difficult to determine the contribution of TF to the clotting time without using an inhibitor of FXIIa.

THROMBOELASTOGRAPHY - Although thromboelastography (TEG) was originally developed over a half a century ago, recent advances and the development of rotational thromboelastometry have resulted in a renewed interest in its use as a test of global coagulation. The two instruments currently available for this purpose are the ROTEM (Rotation Thromboelastometer; Pentapharm GmbH, Munich, Germany) and the Thromboelastograph (Haemoscope Corp., Niles, IL). In the last decade, TEG has been used to assess coagulation in a variety of settings and to monitor adequacy of therapy in hemophilia patients with inhibitors. Details of this test and its various clinical applications are discussed in detail elsewhere in this issue of Seminars in Thrombosis and Hemostasis and not covered here. There is limited data on the use of TEG to specifically evaluate the levels of TF and TFPI. Zillmann and colleagues ${ }^{24}$ showed that the rate of fibrin generation was increased in collagen-treated blood in a TF-dependent manner. A recent publication evaluated the procoagulant potential of cord blood and adult blood using TEG. ${ }^{25}$ In vitro incubation of whole blood with LPS decreased the clotting time, clot formation time, and maximal clot formation in both cord and adult blood, but the effects were more profound in cord blood. Importantly, inhibition of nuclear factor $\mathrm{\kappa B}$ reversed the effects of LPS, suggesting that LPS-induced activation of coagulation was mediated by TF. However, the limitations of whole blood assays discussed previously apply to TEG as well. More studies are needed to assess the ability of TEG to specifically evaluate the contribution of endogenous TF and TFPI to clot formation using clinical samples. 
Direct Methods to Measure Levels of Tissue Factor and Tissue Factor Pathway Inhibitor in Plasma

At present, the only ways to specifically measure levels of TF or TFPI in plasma are using enzyme-linked immunosorbent assay (ELISA), flow cytometry, or activity assays. These are discussed briefly in the next sections.

\section{TISSUE FACTOR AND TISSUE FACTOR PATHWAY INHIBITOR ENZYME-} LINKED IMMUNOSORBENT ASSAY-Several ELISA assays are commercially available to measure TF antigen levels, as well as total and free TFPI antigens (American Diagnostica Inc., Diagnostica Stago, and R\&D systems). The difference between the total TFPI ELISA and the TFPI/Xa complex ELISA lies in their sensitivity. In addition to measuring binary and quaternary TFPI/Xa complexes, the total TFPI ELISA also detects intact and truncated forms of TFPI and complexes of TFPI with TF and FVIIa. The TF ELISA assays have issues with sensitivity and specificity, ${ }^{26}$ and until these issues are addressed they have limited usefulness for the analysis of patient samples. A commercial assay for the detection of MP TF antigen called ZYMUTEST is also available (Hyphen Biomed, Andrésy, France). However, we have found that this assay has low sensitivity compared with our "in-house" MP TF activity assay (see later).

FLOW CYTOMETRY-TF expression on different cells can be detected by flow cytometry using fluorescently labeled antibodies to TF. This approach is well established and routinely used for research purposes. ${ }^{27}$ In addition, flow cytometry can be used to detect TF on MPs. ${ }^{28}$ Recently, Zwicker and colleagues ${ }^{29}$ used an impedance-based flow cytometry method to detect TF-positive MPs in cancer patients. As with the ELISA test, flow cytometry provides information on TF antigen expression but not procoagulant activity. Although flow cytometry has the advantage of also detecting the cellular origin of the TF, sample preparation is time consuming, making it an impractical approach for routine use for $\mathrm{TF}$ detection in a clinical laboratory.

\section{TISSUE FACTOR AND TISSUE FACTOR PATHWAY INHIBITOR ACTIVITY}

ASSAYS-There is also a commercially available assay to measure TF activity (American Diagnostica Inc.). This assay measures FXa generation in the presence of exogenous FVII and FX. Unfortunately, this assay also has issues of specificity, discussed in a recent article. ${ }^{30} \mathrm{TF}$ activity in whole blood can also be measured using frozen anticoagulated whole blood. ${ }^{31}$ Briefly, the blood is thawed to lyse the cells and cellular debris is pelleted by centrifugation and washed before TF activity is measured. TFPI activity is measured by incubating the sample with TF/FVIIa and FX. Residual TF/FVIIa activity is determined by measuring FXa activity using an FXa substrate. TFPI activity is determined using a standard curve.

MEASUREMENT OF MICROPARTICLE TISSUE FACTOR ACTIVITY-MPs can be captured using specific antibodies or, if they express PS, with immobilized annexin V. One assay uses an antibody called 1B10 to capture MPs with subsequent measurement of the levels of TF activity. ${ }^{32} \mathrm{We}$ and others have recently developed an assay for the detection of TF activity in MPs (Fig. 3). ${ }^{11,20}$ Our assay is based on the ability of TF on washed MPs to activate FX in the presence of FVIIa and calcium. ${ }^{20}$ This assay is more sensitive than an "inhouse" ELISA for measurement of TF and is performed in the presence and absence of an anti-TF antibody, which allows determination of TF-dependent FXa generation. ${ }^{12} \mathrm{~A}$ commercial assay that captures PS-positive MPs and measures their TF activity is being developed but has not yet been released (Hyphen BioMed). 


\section{SUMMARY AND CONCLUSION}

In summary, TF and its inhibitor TFPI play essential roles in hemostasis. Increased levels of TF can trigger thrombosis. Currently available tests of global coagulation lack the specificity required to evaluate levels of TF and TFPI. New assays need to be developed before the usefulness of measuring TF (and possibly TFPI) in the management of patients can be evaluated.

\section{Acknowledgments}

We would like to acknowledge Dr. V. Ollivier for CAT assay data, a National Institutes of Health K08 award (R.K.), and grants from the National Institutes of Health (N.M.).

\section{REFERENCES}

1. Gross PL, Weitz JI. New antithrombotic drugs. Clin Pharmacol Ther 2009;86(2):139-146. [PubMed: 19553932]

2. Howard EL, Becker KC, Rusconi CP, Becker RC. Factor IXa inhibitors as novel anticoagulants. Arterioscler Thromb Vasc Biol 2007;27(4):722-727. [PubMed: 17272750]

3. Mackman N, Taubman M. Tissue factor: past, present, and future. Arterioscler Thromb Vasc Biol 2009;29(12):1986-1988. [PubMed: 19923557]

4. Tilley R, Mackman N. Tissue factor in hemostasis and thrombosis. Semin Thromb Hemost 2006;32(1):5-10. [PubMed: 16479457]

5. Censarek P, Bobbe A, Grandoch M, Schrör K, Weber AA. Alternatively spliced human tissue factor (asHTF) is not procoagulant. Thromb Haemost 2007;97(1):11-14. [PubMed: 17200764]

6. Bach RR. Tissue factor encryption. Arterioscler Thromb Vasc Biol 2006;26(3):456-461. [PubMed: 16397140]

7. Maroney SA, Mast AE. Expression of tissue factor pathway inhibitor by endothelial cells and platelets. Transfus Apheresis Sci 2008;38(1):9-14.

8. Hackeng TM, Rosing J. Protein S as cofactor for TFPI. Arterioscler Thromb Vasc Biol 2009;29(12): 2015-2020. [PubMed: 19661488]

9. Heit JA. Cancer and venous thromboembolism: scope of the problem. Cancer Control 2005;12(Suppl 1):5-10. [PubMed: 16179898]

10. Kasthuri RS, Taubman MB, Mackman N. Role of tissue factor in cancer. J Clin Oncol 2009;27(29):4834-4838. [PubMed: 19738116]

11. Tesselaar ME, Romijn FP, Van Der Linden IK, Prins FA, Bertina RM, Osanto S. Microparticleassociated tissue factor activity: a link between cancer and thrombosis? J Thromb Haemost 2007;5(3):520-527. [PubMed: 17166244]

12. Khorana AA, Francis CW, Menzies KE, et al. Plasma tissue factor may be predictive of venous thromboembolism in pancreatic cancer. J Thromb Haemost 2008;6(11):1983-1985. [PubMed: 18795992]

13. Dahm A, Van Hylckama Vlieg A, Bendz B, Rosendaal F, Bertina RM, Sandset PM. Low levels of tissue factor pathway inhibitor (TFPI) increase the risk of venous thrombosis. Blood 2003;101(11):4387-4392. [PubMed: 12560220]

14. Duering C, Kosch A, Langer C, Thedieck S, Nowak-Göttl U. Total tissue factor pathway inhibitor is an independent risk factor for symptomatic paediatric venous thromboembolism and stroke. Thromb Haemost 2004;92(4):707-712. [PubMed: 15467899]

15. Ariëns RA, Alberio G, Moia M, Mannucci PM. Low levels of heparin-releasable tissue factor pathway inhibitor in young patients with thrombosis. Thromb Haemost 1999;81(2):203-207. [PubMed: 10063992]

16. Bladbjerg EM, Madsen JS, Kristensen SR, et al. Effect of long-term hormone replacement therapy on tissue factor pathway inhibitor and thrombin activatable fibrinolysis inhibitor in healthy postmenopausal women: a randomized controlled study. J Thromb Haemost 2003;1(6):12081214. [PubMed: 12871321] 
17. Amini-Nekoo A, Futers TS, Moia M, Mannucci PM, Grant PJ, Ariëns RA. Analysis of the tissue factor pathway inhibitor gene and antigen levels in relation to venous thrombosis. Br J Haematol 2001;113(2):537-543. [PubMed: 11380428]

18. Sidelmann JJ, Bladbjerg EM, Gram J, Münster AM, Jespersen J. Tissue factor pathway inhibitor relates to fibrin degradation in patients with acute deep venous thrombosis. Blood Coagul Fibrinolysis 2008;19(5):405-409. [PubMed: 18600090]

19. Hoke M, Kyrle PA, Minar E, et al. Tissue factor pathway inhibitor and the risk of recurrent venous thromboembolism. Thromb Haemost 2005;94(4):787-790. [PubMed: 16270631]

20. Ollivier V, Wang J, Manly D, et al. Detection of endogenous tissue factor levels in plasma using the calibrated automated thrombogram assay. Thromb Res 2010;125(1):90-96. [PubMed: 19345399]

21. Haubold K, Rink M, Spath B, et al. Tissue factor procoagulant activity of plasma microparticles is increased in patients with early-stage prostate cancer. Thromb Haemost 2009;101(6):1147-1155. [PubMed: 19492160]

22. Santucci RA, Erlich J, Labriola J, et al. Measurement of tissue factor activity in whole blood. Thromb Haemost 2000;83(3):445-454. [PubMed: 10744152]

23. Marsik C, Quehenberger P, Mackman N, Osterud B, Luther T, Jilma B. Validation of a novel tissue factor assay in experimental human endotoxemia. Thromb Res 2003;111(4-5):311-315. [PubMed: 14693180]

24. Zillmann A, Luther T, Müller I, et al. Platelet-associated tissue factor contributes to the collagentriggered activation of blood coagulation. Biochem Biophys Res Commun 2001;281(2):603-609. [PubMed: 11181090]

25. Koch L, Hofer S, Weigand MA, Frommhold D, Poeschl J. Lipopolysaccharide-induced activation of coagulation in neonatal cord and adult blood monitored by thrombelastography. Thromb Res 2009;124(4):463-467. [PubMed: 19477486]

26. Parhami-Seren B, Butenas S, Krudysz-Amblo J, Mann KG. Immunologic quantitation of tissue factors. J Thromb Haemost 2006;4(8):1747-1755. [PubMed: 16879217]

27. Luther T, Flössel C, Hietschhold V, Koslowski R, Müller M. Flow cytometric analysis of tissue factor (TF) expression on stimulated monocytes-comparison to procoagulant activity of mononuclear blood cells. Blut 1990;61(6):375-378. [PubMed: 2291987]

28. Shet AS, Aras O, Gupta K, et al. Sickle blood contains tissue factor-positive microparticles derived from endothelial cells and monocytes. Blood 2003;102(7):2678-2683. [PubMed: 12805058]

29. Zwicker JI, Liebman HA, Neuberg D, et al. Tumor-derived tissue factor-bearing microparticles are associated with venous thromboembolic events in malignancy. Clin Cancer Res 2009;15(22): 6830-6840. [PubMed: 19861441]

30. Bogdanov VY, Cimmino G, Tardos JG, Tunstead JR, Badimon JJ. Assessment of plasma tissue factor activity in patients presenting with coronary artery disease: limitations of a commercial assay. J Thromb Haemost 2009;7(5):894-897. [PubMed: 19220730]

31. Key NS, Slungaard A, Dandelet L, et al. Whole blood tissue factor procoagulant activity is elevated in patients with sickle cell disease. Blood 1998;91(11):4216-4223. [PubMed: 9596669]

32. Aras O, Shet A, Bach RR, et al. Induction of microparticleand cell-associated intravascular tissue factor in human endotoxemia. Blood 2004;103(12):4545-4553. [PubMed: 14988149] 


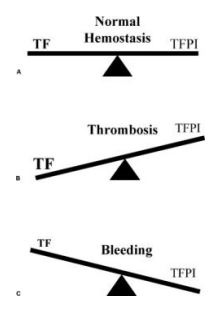

Figure 1.

Role of tissue factor (TF) and tissue factor pathway inhibitor (TFPI) in hemostasis and thrombosis. (A) Depiction of the counterbalancing roles of TF and TFPI in normal individuals. (B) There is a propensity toward thrombosis when TF levels increase and the ability of TFPI to inhibit TF is overwhelmed. (C) Low levels of TF could conversely be associated increased risk for bleeding. This has been shown in mouse models but has not been reported in humans. 


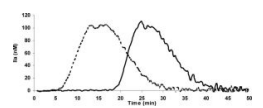

Figure 2.

Impact of tissue factor on the calibrated automated thrombogram (CAT) assay. CAT assay using platelet-poor plasma prepared from whole blood with (dotted line) or without (bold line) LPS treatment for 5 hours. 

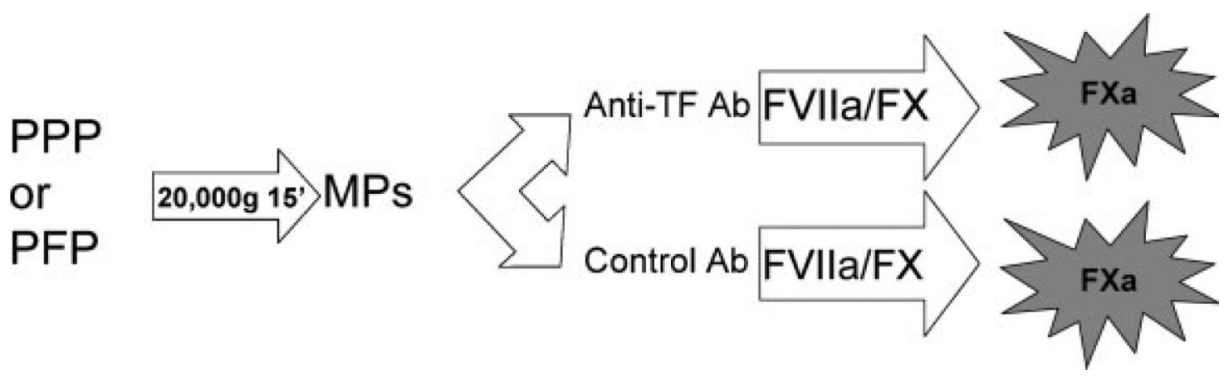

Figure 3.

Schematic for microparticle (MP) tissue factor (TF) procoagulant activity assay. Study sample (either platelet-poor plasma [PPP] or platelet-free plasma [PFP]) is centrifuged at 20,000 $\mathrm{g}$ for 15 minutes at $4^{\circ} \mathrm{C}$ to pellet MPs. These are resuspended in buffer. The samples are then incubated for 15 minutes with either the human TF antibody HTF1 or a control antibody. This is followed by the addition of factors (F)VIIa, X, and calcium and incubation for 2 hours at $37^{\circ} \mathrm{C}$. FXa generation is then stopped by the addition of ethylenediaminetetraacetic acid, and FXa generation is measured based on cleavage of the chromogenic substrate S2765. TF activity is calculated using a reference standard curve generated using relipidated, recombinant TF and the TF-dependent FXa generation is determined by calculating the difference between FXa generation in the presence of hTF1 and control antibodies. For details, see Khorana et al. ${ }^{12}$ 
Table 1

Laboratory Tests of Global Coagulation and Direct Assays of Tissue Factor/Tissue Factor Pathway Inhibitor*

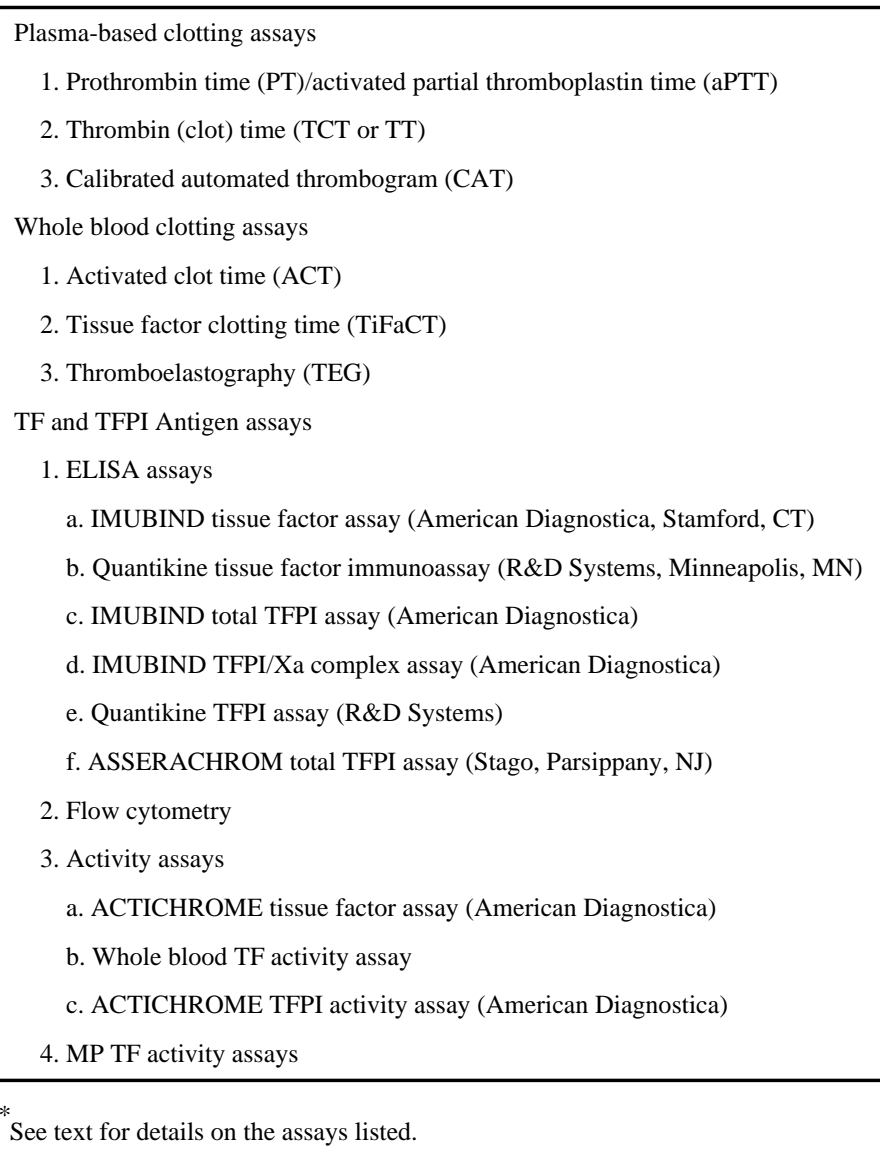

